\title{
ПРЕПОДАВАНИЕ ХИМИИ В ШКОЛЕ НА ОСНОВЕ АДАПТАЦИОННОЙ СИСТЕМЫ ОБУЧЕНИЯ
}

\section{TEACHING CHEMISTRY AT SCHOOL BASED ON THE ADAPTIVE TRAINING SYSTEM}

\section{E. Nelyubina \\ L. Panfilova}

Summary: The interaction of student, teacher and subject of study is carried out under the influence of a huge number of different factors. As a result, there are qualitative changes in the learning process, both positively and negatively affecting the achievement of the set didactic goal. Therefore, it is important to manage the appropriate changes, specifically structuring (hierarchically ordering) the components of the learning process.

Such structuring must be carried out within the framework of a personal approach, in accordance with which it is assumed that the student's personality is treated as a unique individuality, the creation of favorable conditions for its development, self-determination and self-realization through education. This approach reflects the essence of the modern pedagogical concept, the implementation of the ideas of which requires a revision of the goals and values of education, the content and methods of teaching, i.e. formation of personality-oriented systems of training and education.

An adaptive learning system involves the introduction into practice of as many tasks as possible, translated by the teacher into mutual control and self-control of the students. This promotes the development of creativity of the students themselves, who can prepare their own assignments and their solutions to deliver them to the collection of materials with feedback.

Students can workindependently, both collectively in pairs, and separately (individually), performing tasks of different sizes and difficulties.

During the organization of the teacher's work with the students in the lesson, it is necessary to regularly teach them the techniques of independent work: mutual control, mutual learning, mutual evaluation, self-control and self-assessment. It is necessary, together with the students, to work out the organizational forms of collective (paired) independent work, including these forms of work in small doses in the process of explaining new material at the stage of its consolidation.

The relevance of the study is due to the need to resolve the following main contradictions identified by us:

- between the variety of individual and personal characteristics of students and the limited adaptive capabilities of the methods used in teaching chemistry;

- between the explanatory and illustrative way of teaching chemistry, which is dominant in school, and the need to ensure the adaptive nature of educational activity;

- between the need to ensure sustainable formation of subject educational results in chemistry and the lack of a methodology for adaptive teaching of chemistry.

The relevance of this study is due to the fact that it has not only scientific significance (associated with the disclosure of the theory and

\author{
Нелюбина Елена Георгиевна \\ К.п.н., дочент, ФГБОУ ВО «Самарский государственный \\ социально-педагогический университет", г. Самара \\ nelubina.elena@pgsga.ru \\ Панфилова Людмила Владимировна \\ Д.п.н., профессор, ФГБОУ ВО «Самарский государственный \\ социально-педагогический университет», г. Самара \\ panfilova@pgsga.ru
}

Аннотация: Взаимодействие ученика, учителя и предмета изучения осуществляется под воздействием огромного числа различных факторов. В результате происходят качественные изменения процесса обучения, как положительно, так и отрицательно влияющие на достижение поставленной дидактической цели. Поэтому важно соответствующими изменениями управлять, специально структурируя (иерархически упорядочивая) компоненты процесса обучения.

Такое структурирование необходимо осуществлять в рамках личностного подхода, в соответствии с которым предполагается отношение к личности ученика как к неповторимой индивидуальности, создание благоприятных условий для ее развития, самоопределения и самореализации через образование. Этот подход отражает суть современной педагогической концепции, реализация идей которой требует пересмотра целей и ценностей образования, содержания и методов обучения, т.е. формирования личностно ориентированных систем обучения и воспитания.

Адаптивная система обучения предполагает внедрение в практику как можно большего числа заданий, переведенных учителем на взаимоконтроль и самоконтроль обучаемых. Это способствует развитию творчества самих учащихся, которые могут готовить собственные задания и их решения, чтобы доставить их в копилку материалов с обратной связью.

Работать самостоятельно учащиеся могут как коллективно в парах, так и обособленно (индивидуально), выполняя задания разного объема и трудности. Во время организации работы учителя с учащимися на уроке необходимо регулярно, обучать их приемам самостоятельной работы: взаимоконтролю, взаимообучению, взаимооценке, самоконтролю и самооценке. Необходимо совместно с обучающимися отрабатывать организационные формы коллективной (парной) самостоятельной работы, включая эти формы работы небольшими дозами в процесс объяснения нового материала на этапе его закрепления.

Актуальность исследования обусловлена необходимостью разрешения следующих основных противоречий, выявленных нами:

- между многообразием индивидуально-личностных особенностей учащихся и ограниченными адаптивными возможностями используемых методик обучения химии;

- между доминирующим в школе объяснительно-иллюстративным способом обучения химии и необходимостью обеспечения адаптивного характера образовательной деятельности;

- между необходимостью обеспечения устойчивого формирования предметных образовательных результатов по химии и отсутствием методики адаптивного обучения химии.

Актуальность данного исследования обусловлена тем, что оно имеет не только научное значение (связанное с раскрытием теории и методики АСО), но и социальное значение (способствующее адаптации личности ученика школы 
methodology of ASO), but also social significance (contributing to the adaptation of the personality of the school student in society), as well as applied (associated with the development and implementation of the ASO methodology at school).

The research problem is due to the need to develop guidelines for the application of an adaptive approach to teaching in chemistry.

\section{Purpose.}

The purpose of the research is to describe the methodological aspects of the implementation of the adaptive system of teaching chemistry, aimed at the formation of subject universal educational actions.

Method or methodology of the work: to date, the following steps have been taken in pedagogical science to develop an adaptive teaching system: pedagogical technologies of an adaptive school and an adaptive education system (N.P. Kapustin), an adaptive control system (A.M. Moiseev, T.I. Shamova, TI Davydenko and others); issues of adaptive control technology (G.K. Zaitsev, N.K. Kovsh, V.A. Milkop and others), adaptive school as a model of an educational institution (N.P. Kapustin, I.S. Yakimanskaya, E.A. Yamburg and others), as well as the philosophy of the subjective-humanistic approach to education (M.M. Bakhtin, N.A. Berdyaev, Yu.M. Lotman, etc.), the main provisions of the theory of knowledge and the theory of personality development (B. Ananiev, A.V. Brushlinsky, L.S. Vygotsky, A.N. Leontiev, B.F. Lomov, V.S. Merlin, K.K. Platonov and others), psychodiagnostics (G.D. Eysenck, V.M. Bleicher, A.A. Bodalev, L.F. Burlachuk, V.N. Druzhinin, P. Kline, F. Fransella, D. Bannister, R. Kettel, D. Gilford and others), theoretical foundations of didactics (B.S. Gershunsky, M.A. Danilov, V.I. Zagvyazinsky, I.Ya. Lerner, N.D. Nikandrov, M.N. Skatkin, A.V. Khutorskoy, etc.) and personalityoriented pedagogy (N.A. Alekseev, D.A. Belukhin, E.V. Bondarevskaya, V.V.Serikov, I.S. Yakimanskaya and others), methods of analysis of pedagogical systems developed by V.I. Zagvyazinsky, T.A. Ilyina, G.D. Kirillova, F.F. Korolev, N.V. Kuzmina, Yu.N. Kuljutkin, I.D. Pekhletsky, M.M. Potashnik, G.N. Sukhobskaya, G.I.Shchukina and others; ideas of creative development and self-development of personality (V.I. Andreev, D.B. Bogoyavlenskaya, Ya.A. Ponomarev, N.Yu. Postalyuk and others), its professional development (S.A. Dneprov, N.V. Kuzmina, Yu.I. Tarsky, V.D. Shirshov and others), methods of using the mathematical apparatus in pedagogical research (B.P. Bitinas, M.I. Grabar, N.F. Dzhuzha, L.B. Itelson, I.P. Lebedeva, D. Lawley, V.I. Mikheev, I.D. Pekhletsky, S.V. Rusakov, G.V. Sukhodolsky and others).

Results:

- the theoretical significance of the study is as follows: the methodological conditions for the implementation tion of methods of adaptive teaching of chemistry at school; systematized data on the methodological apparatus of the adaptive learning system.

- the practical significance of the research lies in the fact that: selected and partially compiled didactic materials for conducting chemistry lessons in grades 8-9 based on an adaptive learning system; materials and results of the research can be replicated in educational institutions of the Russian Federation.

Practical implications: the results obtained are advisable to apply in educational institutions.

Keywords: adaptive learning system, teaching methods of chemistry, individual assignments, work in pairs. в социуме), а также прикладное (связанное с разработкой и реализацией методики АСО в школе).

Проблема исследования обусловлена необходимостью разработки методических рекомендаций по применению адаптивного подхода к обучению по химии.

Цель исследования - описать методические аспекты реализации адаптивной системы обучения химии, направленные на формирование предметных универсальных учебных действий.

Метод или методология проведения работы: к настоящему времени в педагогической науке сделаны следующие шаги по разработке адаптивной системы преподавания: педагогические технологии адаптивной школы и адаптивная система образования (Н.П. Капустин), адаптивная система управления (А.М. Моисеев, Т.И. Шамова, Т.И. Давыденко и др.); вопросы технологии адаптивного управления (Г.К. Зайцев, Н.К. Ковш, В.А. Милькоп и др.), адаптивная школа как модель образовательного учреждения (Н.П. Капустин, И.С. Якиманская, Е.А. Ямбург и др.), а так же философия субъектно-гуманистического подхода к образованию (М.М. Бахтин, Н.А. Бердяев, Ю.М. Лотман и др.), основные положения теории познания и теории развития личности (Б.Г. Ананьев, А.В. Брушлинский, Л.С. Выготский, А.Н. Леонтьев, Б.Ф. Ломов, В.С. Мерлин, К.К. Платонов и др.), психодиагностики (Г.Д.Айзенк, В.М.Блейхер, А.А.Бодалев, Л.Ф.Бурлачук, В.Н.Дружинин, П. Клайн, Ф. Франселла, Д. Баннистер, Р. Кеттел, Д. Гилфорд и др.), теоретические основы дидактики (Б.С. Гершунский, М.А.Данилов, В.И. Загвязинский, И.Я. Лернер, Н.Д. Никандров, М.Н. Скаткин, А.В. Хуторской и др.) и личностно ориентированной педагогики (Н.А. Алексеев, Д.А. Белухин, Е.В. Бондаревская, В.В. Сериков, И.С. Якиманская и др.), методы анализа педагогических систем, разработанные В.И. Загвязинским, Т.А. Ильиной, Г.Д. Кирилловой, Ф.Ф. Королевым, Н.В. Кузьминой, Ю.Н. Кулюткиным, И.Д. Пехлецким, М.М. Поташником, Г.Н. СухобСкой, Г.И. Щукиной и др.; идеи творческого развития и саморазвития личности (В.И. Андреев, Д.Б. Богоявленская, Я.А. Пономарев, Н.Ю. Посталюк и др.), ее профессионального становления (С.А. Днепров, Н.В. Кузьмина, Ю.И. Тарский, В.Д. Ширшов и др.), методы использования математического аппарата в педагогическом исследовании (Б.П. Битинас, М.И. Грабарь, Н.Ф. Джужа, Л.Б. Ительсон, И.П. Лебедева, Д. Лоули, В.И. Михеев, И.Д. Пехлецкий, С.В. Русаков, Г.В. Суходольский и др.).

\section{Результаты:}

- теоретическая значимость исследования заключается в следующем: описаны методические условия реализации методики адаптивного обучения химии в школе; систематизированы данные по методологическому аппарату адаптивной системы обучения.

- практическая значимость исследования заключается в том, что: подобраны и частично составлены дидактические материалы для проведения уроков химии в 8-9 классе на основе адаптивной системы обучения; материалы и результаты исследования могут быть тиражированы в образовательных учреждениях РФ.

Область применения результатов: полученные результаты целесообразно применять в образовательных учреждениях.

Ключевые слова: адаптивная система обучения, методика преподавания химии, индивидуальные задания, работа в парах. 
Сущность адаптивного подхода в том, что в биологической и в социальной жизни человека к успеху ведет адаптация, так как для успеха в жизни любой личности следует отыскать оптимальный в целях себе уровень стресса также использовать адаптационную энергию в таком темпе и направлении, что отвечает прирожденным отличительным чертам и предпочтениям. Нынешние учебные заведение формирует требование с целью оптимального расходования адаптационной энергии средствами преподавательской помощи участникам просветительного процесса [2].

$\mathrm{B}$ основу своей работы мы положили программу О.С. Габриеляна. Работа осуществлялась в 2018-2020 учебном году в 8-9 классах ГБОУ СОШ «ОЦ» с. Тимашево Самарской области.

Так как учащиеся 8 классов только начинают изучение химии, то нам было тяжело оценить уровень форсированности у них предметных УУД.

Поэтому основной педагогический эксперимент был проведен с обучающимися 9-х классов, которые работали по данной системе уже в 8 классе в 2018-2019 учебном году. Адаптационная система преподавания химии так же применялась в 2019-2020 учебном году в 9 классе. С этой целью мы составляли и корректировали задания по химии для организации индивидуальной самостоятельной или групповой работы под руководством учителя.

Ученики 9 классов были разбиты на 4 группы в зависимости от таких критериев как уровень обученности, стиль мышления и ведущая модальность.

\section{Особенности групп заключаются в том, что:}

Группа 1. У учащихся этой группы обученности на уровне узнавания. Они не могут воспринимать изученный материал по химии, но узнают химические объекты (понятия, законы и т.д.) по их существенным признакам.

Группа 2. У учащихся этой группы уровень обученности-воспроизведение. Они могут пересказать содержание текста, правила, положения, теоретическое утверждение.

Группа 3. У учащихся этой группы уровень обученности-применение. Они могут применять на практике полученные теоретические знания, решать задачи с использованием усвоенных законов и правил, вскрывать причинно-следственные связи.

Группа 4. У учащихся этой группы уровень обученности- трансформация. Они могут переносить знания из одной системы в другую. Используют знания в нестан- дартных ситуациях.

Для каждой из этих групп, кроме того, учитывается стиль мышления (левополушарный-Л, равнополушарный-Р, правополушарный-П) и ведущая модальность восприятия и усвоения информации (аудиальная-А, визуальная-В, кинестетическая-К). Подготовка к работе осуществлялась совместно с психологом образовательного учреждения, поэтому учащиеся были разбиты на 12 мини-подгрупп, которые выполняли разно-уровневые задания, характеристика которых представлена в таблице 1.

Таблица 1.

Типы учебных адаптивных заданий по химии.

\begin{tabular}{|c|c|c|c|}
\hline \multirow{3}{*}{$\begin{array}{l}\text { Уровни обученности } \\
\text { учащихся }\end{array}$} & \multicolumn{3}{|c|}{ Стили мышления и ведущие модальности учащихся } \\
\hline & $\begin{array}{l}\text { Лево- } \\
\text { полушарное } \\
\text { мышление-Л }\end{array}$ & $\begin{array}{l}\text { Равно- } \\
\text { полушарное } \\
\text { мышление-Р } \\
\end{array}$ & $\begin{array}{l}\text { Право- } \\
\text { полушарное } \\
\text { мышление-П }\end{array}$ \\
\hline & $\begin{array}{l}\text { Аудиальная } \\
\text { модальность-А }\end{array}$ & $\begin{array}{l}\text { Визуальная } \\
\text { модальность-В }\end{array}$ & $\begin{array}{l}\text { Кинесте- } \\
\text { тическая } \\
\text { модальность-К }\end{array}$ \\
\hline 1-Узнавание & $1 Л А$ & $1 \mathrm{~PB}$ & $1 П K$ \\
\hline 2-Воспроизведение & $2 Л А$ & $2 P B$ & $2 \Pi K$ \\
\hline 3.Применение & ЗЛА & $3 P B$ & $3 П K$ \\
\hline 4-Трансформация & $4 Л А$ & $4 \mathrm{~PB}$ & $4 \Pi K$ \\
\hline
\end{tabular}

Таким образом, в разработанной адаптивной системе преподавания химии используется 12 типов адаптивных заданий, позволяющих устранить пробелы, обобщить и систематизировать знания учащихся, а также сформировать предметные образовательные результаты.

Учащимся с уровнем обученности - узнавание предлагаются задания, ориентированные на запоминание учебного материала и его воспроизведение. Для таких учащихся разрабатываются и реализуются задания не только на узнавание (требующие таких умственных операций, как сопоставление, выбор, сравнение), но и на воспроизведение (требующие таких практических действий, как рисование, написание, пересказ). Поскольку задания на воспроизведение для некоторых учащихся могут быть непосильными, то предусматривается дозированная помощь учителя.

Приведем пример задания типа 1ЛА (для учащихся с уровнем обученности узнавание, левополушарным стилем мышления и аудиальной модальностью). Задания зачитываются устно.

1.Вставьте правильный ответ: Металлы - это ..., обладающие специфическим металлическим блеском, пластичностью, высокой теплопроводностью и электропроводностью

а) непрозрачные вещества 
б) прозрачные вещества

в) полые вещества

2. Дайте ответ. Как называется прочесс восстановления металлов из их руды с помощью угля, угарного газа, водорода при нагревании? [9]

3.Пользуясь карточкой «классы неорганических веществ» вариант 1, назовите по формуле класс соединений, которому она соответствует?

Фрагмент тренажерной карточки

«Классы неорганических соединений»

\begin{tabular}{|c|c|c|c|c|}
\hline Bарианты & $A$ & 5 & $B$ & $\Gamma$ \\
\hline 1 & $\ni \times O^{-2} y$ & ${ }^{m} M e(O H)_{m}$ & $H_{n} A^{n}$ & ${ }^{m} M e_{n} A_{m}^{n}$ \\
\hline
\end{tabular}

Учащимся с уровнем обученности - воспроизведение предлагаются задания на выявление взаимосвязи между химическими объектами, на установление причинно-следственных связей. Для таких учащихся разрабатываются и реализуются задания не только на понимание (требующие таких практических действий, как рисование, написание, пересказ), но и установление причинно-следственных связей.

Приведем пример задания типа 2РВ (для учащихся с уровнем обученности воспроизведение, равнополушарным стилем мышления и визуальной модальностью).

1. Запишите уравнения реакций, с помощью которых можно осуществить следующие превращения:

a) натрий $\rightarrow$ пероксид натрия $\rightarrow$ оксид натрия $\rightarrow$ гидроксид натрия $\rightarrow$ сульфат натрия

б) железо $\rightarrow-$-лорид железа (2) $\rightarrow$ хлорид железа (3) $\rightarrow$ гидроксид железа (3) $\rightarrow$ оксид железа (3) $\rightarrow$ железо

в) кальций $\rightarrow$ оксид кальция $\rightarrow$ гидроксид кальция $\rightarrow$ - карбонат кальция $\rightarrow$ гидрокарбонат кальция $\rightarrow$ карбонат кальция $\rightarrow$ хлорид кальция $\rightarrow$ кальций

2. Составьте уравнение реакции диспропориионирования хлора в горячем растворе гидроксида калия. Сумма коэффичиентов в полученном уравнении равна Запишите число.

3. Покажите, где в Периодической системе размещены элементы металлов в главных и побочных подгрупnax.

Учащимся с уровнем обученности - применение предлагаются задания, ориентированные на применение учебного материала в стандартных ситуациях. Для таких учащихся разрабатываются и реализуются задания на применение (требующие таких умственных операций как выполнение по образцу, по правилу, по формуле, сопоставление что-то с чем-то).
Приведем пример задания типа ЗПК (для учащихся с уровнем обученности применение, правополушарным стилем мышления и кинестетической модальностью).

1. Используя схему, напишите уравнения реакций. Объясните окислительно-восстановительные прочессы, обозначенные звездочкой.

a) $\mathrm{M}+\mathrm{O}_{2} \rightarrow \mathrm{M}_{2} \mathrm{O} \rightarrow \mathrm{MO} \rightarrow \mathrm{M}+(p-p) \rightarrow M^{+}$

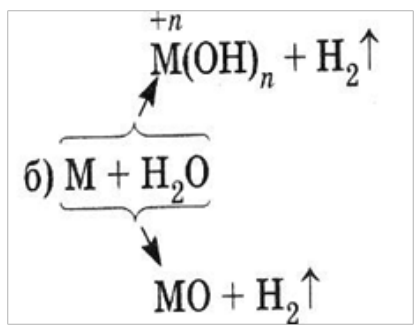

2.Укажите соответствие между химической формулой вещества и его названием:

\begin{tabular}{|l|l|}
\hline $\mathrm{CH}_{4}$ & Апитьевая сода \\
$\mathrm{SiH}_{4}$ & Бметан \\
$\mathrm{K}_{2} \mathrm{CO}_{3}$ & В силан \\
$\mathrm{Na}_{2} \mathrm{CO}_{3}$ & Гпоташ \\
$\mathrm{NaHCO}_{3}$ & Д кальцинированная сода \\
\hline
\end{tabular}

Учащимся с уровнем обученности - трансформация предлагаются тренинговые задания на перенос учебного материала в нестандартную ситуацию. Для таких учащихся разрабатываются и реализуются задания продуктивно-информационные (расширяющие объем химической информации), проблемные, творческие (логарифм, метаграмма, анаграмма, шарада, рефераты, сказки).

В начале изучения темы «Металлы» можно предложить учащимся темы для творческих работ:

1. Роль металлов в развитии человеческой цивилизации,

2. История одного металла,

3. Значение металлов и сплавов в современной технике,

4. Использование металлов в искусстве,

5. Этому металлу принадлежит будущее.

К любой из обозначенных тем предложить учащимся сделать рекламный плакат (для учащихся с равнополушарным стилем мышления, визуальной модальностью) или репортаж (для учащихся с левополушарным стилем мышления, аудиальной модальностью). Для равнополушарных визуалов можно предложить составить описательную сказку. Для левополушарных аудиалов можно предложить составить сказку-диалог.

Чтобы поддержать интерес учащихся-кинестетиков 
с правополушарным стилем мышления можно предложить им в течение месяца, пользуясь учебником и дополнительной литературой, составить 15 текстовых практико-ориентированных вопросов по данной теме для игры «Кто хочет стать знатоком по химии металлов?» (с градацией вопросов от простых к сложным). Из всех предложенных вопросов можно выбрать наиболее интересные и составить сценарий игры [9].

Адаптивное совершенствование и применение знаний и умений можно провести в форме групповой работы, используя наиболее типовые варианты заданий (ЛА, ПК, РВ с уровнем обученности воспроизведение и применение). К примеру, это может быть урок-обобщение по одному из разделов, на котором будут представлены задания для каждого типа обученности.

В ходе проведения педагогического эксперимента установлена актуальность реализации и разработки адаптивной системы обучения химии, доказана эффективность разработанных подходов к внедрению адаптивной система преподавания химии в общеобразовательные учреждения.

Подводя итог проведенного исследования, можно утвердительно сказать, что цель исследования достигнута. Результаты работы могут быть использованы педагогами для формирования предметных образовательных результатов по химии.

\section{ЛИТЕРАТУРА}

1. Васильева П.Д. Обучение химии / П.Д. Васильева, Н.Е. Кузнецова. - СПб.: КАРО, 2003. - 128 с.

2. Власова Е.3. Адаптивное обучение на новом витке развития педагогических идей // Наука и школа. — 1999. — №5. — C.2-9.

3. Гаученова М.А., Смирнова Т.С. Система учебных заданий в личностно-ориентированном обучении химии // Из сб.: Вечерняя сменная школа: проблемы и факторы развития. СПБ.: ИОВ РАО. -1997. - С.80-82.

4. Границкая А.С. Научить думать и действовать. Адаптивная система обучения в школе. М.: Просвещение, 1991.

5. Гузеев В.В. Групповая деятельность учащихся в образовательном процессе / В.В. Гузеев // Химия в школе. 2003. № 2. - С. 15-25.

6. Капустин Н.П. Педагогические технологии адаптивной школы/Н.П. Капустин //М.,1999г

7. К Кандаурова А.Н. Адаптивная технология уроков на основе теории развивающего обучения // Школа. 2003. - №3. - С.37-40.

8. Каплунович С.М. Психолого-педагогические методы естественной диагностики структуры мышления учащихся / С.М. Каплунович // Вестник Новгородского государственного университета: Серия «Пе-дагогика и психология». - 2009. - № 53. - С. 72-75.

9. К Капулин Д.В., Русских П.А. Адаптивный подход к обучению с применением современных информационных технологий. В сборнике: Инновационные технологии в науке и образовании сборник статей VI Международной научно-практической конференции: в 2 частях. 2017. С. 91-96.

10. Царев Р.Ю., Тынченко С.В., Гриценко С.Н. Адаптивное обучение с использованием ресурсов информационно-образовательной среды. Современные проблемы науки и образования. 2016. № 5. С. 219.

11. Ярмоленко Н.В. Пути построения адаптивной системы управления обучением. Современная система образования и перспективные направления развития. Сборник научных трудов. Под общ. ред. В.Ф. Купавского. Пермь, 2017. С. 250-253. 